\title{
INVESTIGATION OF HOUSING PREFERENCES IN VIEW OF THE HOUSING MARKET DYNAMICS IN DOHA METROPOLITAN
}

\author{
Hatem Ibrahim $^{(1)^{*}}$, Ashraf Salama ${ }^{(2)}$, Florian Wiedmann ${ }^{(2)}$, Reem Awwaad $^{(\mathbf{1})}$, and Bassma Aboukalloub ${ }^{(1)}$ \\ (1) Department of Architecture and Urban Planning, College of Engineering, Qatar University \\ (2) Department of Architecture, University of Strathclyde Glasgow, United Kingdom \\ *Corresponding author's email: hatem_ibrahim@qu.edu.qa
}

\begin{abstract}
Since the 2000s, Doha went through enormous economic growth and urbanization processes. The massive migration inflows have suggested particular housing preferences that are driven by the demographic and lifestyle diversities of the multicultural population. Housing preferences of the multicultural population are defined in terms of housing location, cost, and typology. The paper aims to study housing preferences in view of the housing market dynamics in order to recommend future actions for housing planning and expansion. It focuses on the period from 2000 to 2017 where rapid urban development took place in Doha metropolitan considering cultural, sporting, economic, real estate, and political incidents. The methodological approach includes: questionnaire survey of housing preferences, and survey of the perceptions of housing market experts. The paper defines the major shifts in the housing market based on: the sporting events, construction boom, and real-estate boom. It will discuss solutions to reduce the gap between housing supply and demand. Also, it will conclude actions for future housing expansion based on the recommendations by key market experts towards a sustainable local economic growth.
\end{abstract}

Keywords: Housing Preferences; Multicultural Population; Housing Market; Doha Metropolitan.

\section{INTRODUCTION}

The rapid urbanization and the massive inflows of the multicultural population have posed significant questions to the housing market in Doha metropolitan. Today, Doha's multicultural population is made-up of four main cultural groups: Qataris, Arabs, Asians, and Westerners. In this paper, Qataris are referred to as nationals; while Arabs, Asians, and Westerners are referred to as migrants. In 2016, migrants have made-up 88\% of Qatar's total population (Snoj, 2017). This reflects the intensity of multi-cultures where the needs of each cultural group are different.

Studying the housing preferences will aid in developing sustainable neighborhoods (Petkar and Macwan, 2013). Housing preferences are known to be related to demographic factors on how nationals and migrants are residing in the city (Haybatollahi et. al., 2015). The demographic structure of the nationals is different than that of migrants. Housing preferences can be defined as the expression of the quantity and quality of housing features (Lee et. al., 2008; Hunt, 2010; Ouwehand and Doff, 2011). In this paper, housing preferences are defined by three factors: location, cost, and typology.

\section{RESEARCH METHODOLOGY}

\subsection{Research Tools}

The paper uses a quantitative and qualitative research methods through the following tools:

1. Survey of housing preferences that is conducted through a questionnaire, which is distributed for 388 residents in Doha to study the demographic pattern of the multicultural population.

2. Survey of experts' perceptions in the housing market is conducted through face-to-face interviews from local authorities, including real estate developers, architects, urban planners, and academics.

\subsection{Study Area and Period}

Doha metropolitan is composed of Doha municipality, parts of Al-Rayyan, Um Slal, and Al-Daayen municipalities (Figure 1). Throughout the paper, Doha metropolitan is referred to as merely Doha. Neighborhoods in Doha are divided into: downtown, suburban, and waterfront. Downtown neighborhoods represent the old center of Doha up to the C-Ring Road. Suburban neighborhoods include all urban areas around the D, E, and F-Ring roads. Waterfront neighborhoods include the coastal line of Doha, except the part attached to the downtown neighborhoods. 

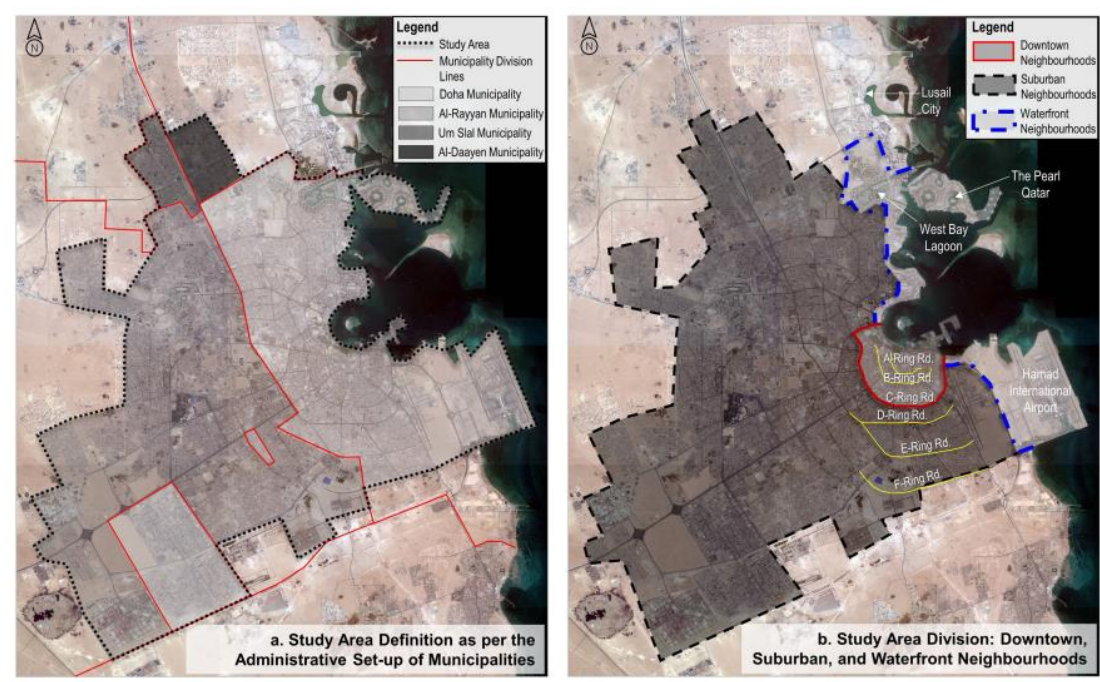

Figure 1. The study area of Doha metropolitan and neighborhood divisions (source: Ministry of Development Planning and Statistics, 2013; Ministry of Municipality and Environment, 2015 "edited by the authors")

The study focuses on the period of rapid housing dynamics, starting from year 2000 to 2017. The highly relevant incidents during this period have affected the development of housing typologies:

- Sporting events: hosting the Asian Games in 2006, and winning the World Cup bid in 2010.

- Construction boom: the establishment of artificial island of the Pearl Qatar in 2011 and the announcement of Qatar Integrated Railway Project in 2012.

- Real-estate boom: approval of property ownership rule for migrants, established in 2004.

\section{RESEARCH BACKGROUND}

During the 2000s, the housing market in Doha has witnessed the biggest influence of the population's diverse demographics (Figure 2 a). Land use planning was based on residential land use distribution (Jaidah and Bourennane, 2009; Shandas et. al., 2017). Traditionally, the downtown was the most sought-after location for housing in Doha (Eddisford and Carter, 2017). Gradually as the city began to move away from traditional locations into areas around the main ring roads, these locations grew in importance for housing developments (Salama and Wiedmann, 2013). A preference to live near the workplace, school, and lifestyle facilities has guided housing location preferences (Scheiner and Kasper, 2003; Dawkins and Koebel, 2009; Pisman et. al., 2011). Today, the waterfront has become a sought-after location for high-end housing targeting high-income groups such as the West Bay Lagoon, Lusail City, and The Pearl Qatar (Property Market Overview, 2017).

According to Colliers International (2014), 70\% of Doha's population are low-income groups (Figure 2 b). Since 70\% of Doha's population earn a monthly salary form 5,000 QR to 19,999 QR (low-income group), they are not able to find their appropriate housing based on their preferences. This can be due to the rapid population growth, which has created a shortage of affordable housing supply. Since the existing supply of housing targets middle to high-income groups, therefore it can be stated that the housing needs of Doha's population are not met. This reflects the strong need for affordable housing. This also implies the influence of affordability levels on housing preferences, which makes the population compromise their housing needs in order to save costs. Although the government is seeking to address this issue, affordable housing is expected to remain in short supply.
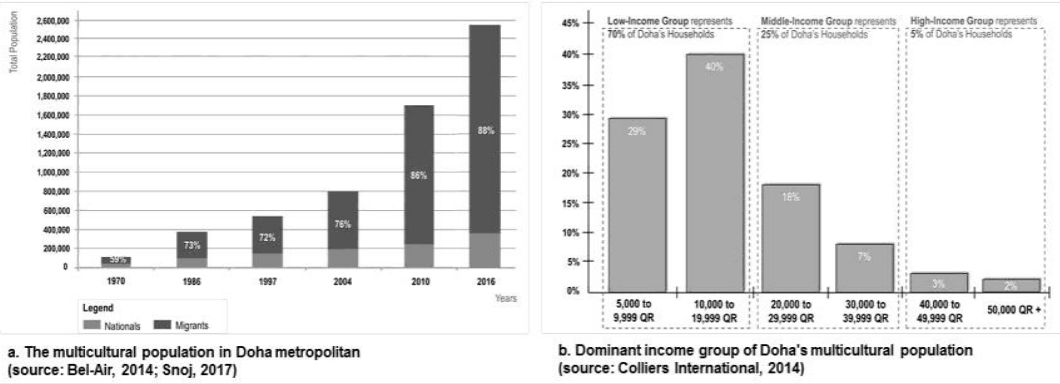

Figure 2. Characteristics of the multicultural population in Doha metropolitan (source: developed by the authors) 
The housing market has mirrored the urban changes in Doha. The population has steadily moved away from the high-density downtown into suburban and waterfront locations. According to Colliers International (2013), most of the nationals live in villas in suburban neighborhoods, while most of migrants live in apartments in downtown neighborhoods. This has shaped the housing dynamics in Doha where apartments are dominating the market (Wiedmann et. al, 2012). Therefore, it can be concluded that housing demand in terms of typologies is clearly defined by nationality.

\section{HOUSING PREFERENCES AND THE MARKET DYNAMICS}

The analysis of the questionnaires reflects almost the actual demographic and housing conditions of Doha. The existing demographic composition of the population is clearly reflected in which $92 \%$ of total respondents are migrants, which reflects that the majority of Qatar's population are migrants. In terms of the cultural mix, Asians are the largest cultural group in Doha, which is reflected in the questionnaire where $41 \%$ of the respondents are Asians (Figure 3 a). In terms of gender, male respondents are more than female respondents, (Figure 3 b), which is confirmed by the Bel-Air (2014), where men have outnumbered women by almost 1 to 5 .
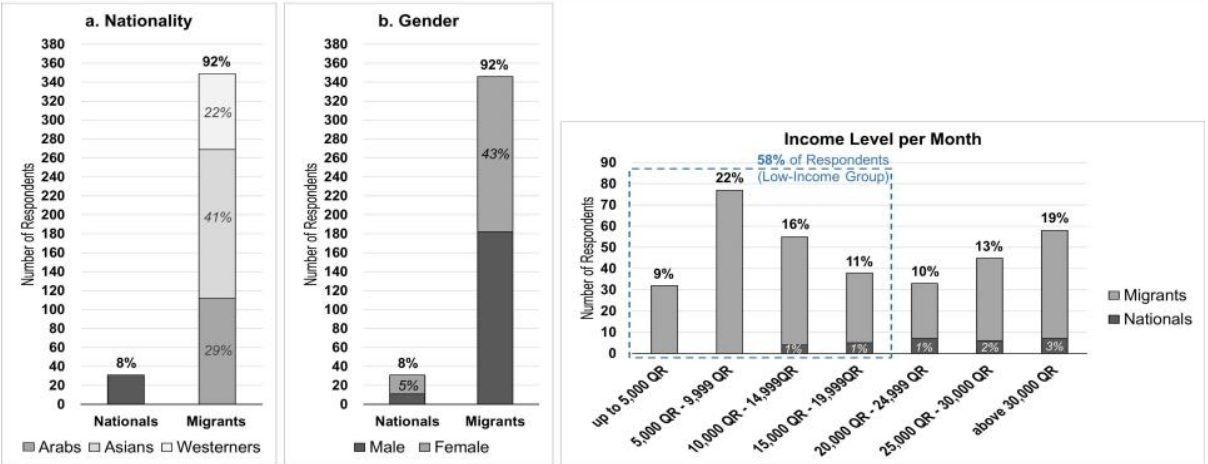

Figure 3. Demographic data of respondents (source: the authors based on the questionnaire survey)

\subsection{Housing Location}

It is concluded that $53 \%$ of the respondents live in suburban neighborhoods, where single-family housing (villa typology) is popular. Whereas 33\% live in downtown neighborhoods, and $14 \%$ live in waterfront neighborhoods where multi-family housing (apartment typology) is popular (Figure 4 a). In terms of housing location preferences, 39\% prefer living in waterfront neighborhoods, in which 38.5\% of them are migrants, which reflects their strong preference for waterfront neighborhoods. This can be due to the real estate law that allows housing ownership for migrants. However, nationals prefer suburban neighborhoods in which 7\% prefer suburban neighborhoods (Figure 4 b).
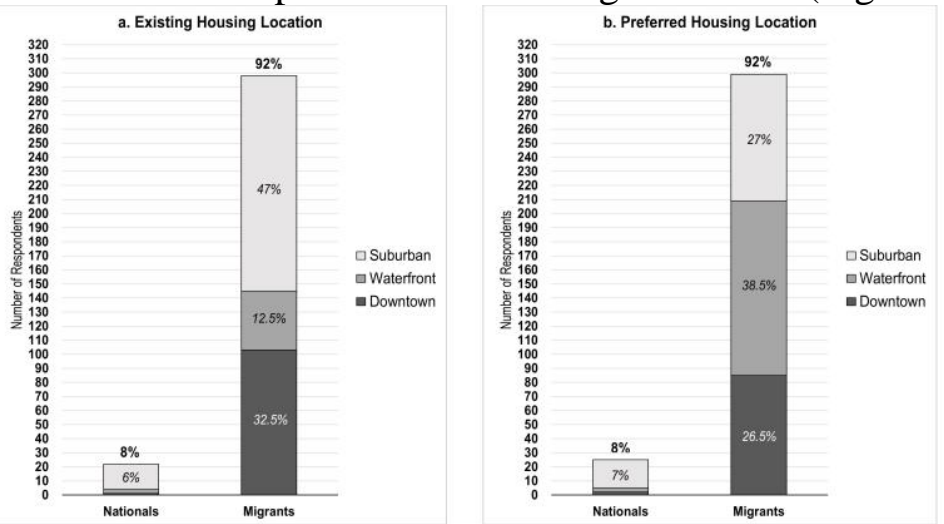

Figure 4. Housing location preferences (source: the authors based on the questionnaire survey)

Experts have agreed that the governmental vision is the main driver for urban and population growth in Doha. Major incidents took place resulting in construction and real estate booms in the city. However, housing developments have been impacted by a number of factors related to planning and zoning, accessibility, and equity. Zoning and building regulations have the greatest impact on housing developments where most of the existing housing designs are not committed to the local culture, climate, and context. 


\subsection{Housing cost}

In terms of housing costs analysis, $90.5 \%$ of respondents live in rental housing where migrants are the majority (90\%), (Figure 5 a) and would still prefer to rent (63\%), (Figure $5 \mathrm{~b}$ ). This can be due to the income level and short-term stay in Doha. In reference to the nationals housing which the government commonly supports, $7.5 \%$ own their houses and $8 \%$ would prefer to own. The housing market has been affected by the multiplicity of income level diversities. However, this is not the case with nationals where almost all of them are house owners (7.5\%). Therefore, housing rentals play a considerable role in adjusting housing preferences in Doha where the ideal housing environment can be compromised in order to save costs, especially for migrants (67\%), (Figure $5 \mathrm{c}$ ).

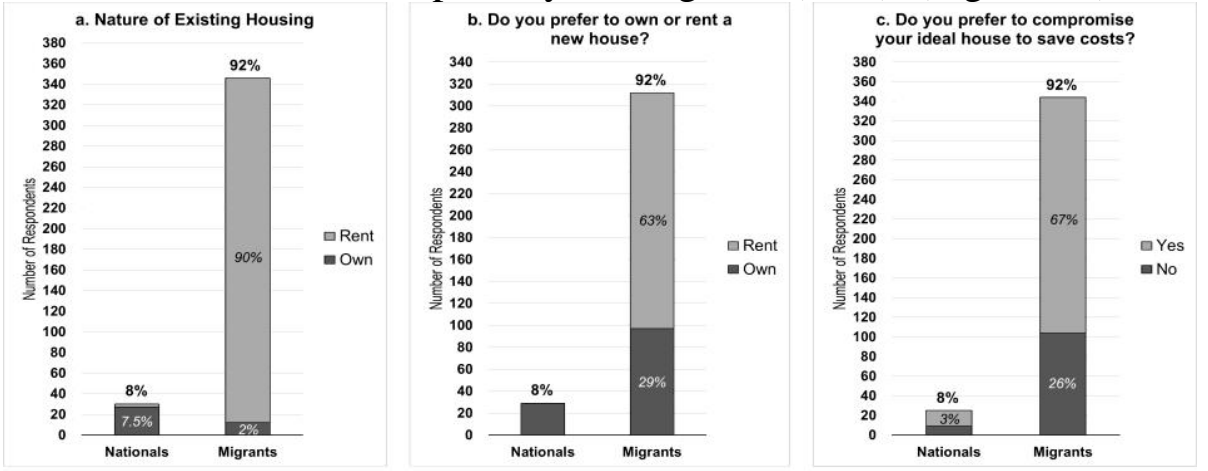

Figure 5. Housing cost preferences (source: the authors based on the questionnaire survey)

Typically, the income level drives housing preferences in Doha. Nationals tend to value community residence and spaciousness (housing location and typology). On the other hand, migrants tend to value costs and affordable living (housing cost). Therefore, affordability is among the significant reasons for favouring apartments especially for single migrant workers.

Experts have focused on the growth of population in Doha, and referred to the construction boom in 2004 that increased the migration flows. It can be concluded that the housing market of Doha lacks the standard levels of affordability. Low-income migrants struggle to find their appropriate housing. The improved housing regulations and policies can address this need through regulating housing prices and quality.

\subsection{Housing Typology}

In terms of housing typologies analysis, $64 \%$ of the migrants live in apartments (Figure 6 a). Yet, only $27.5 \%$ of migrants prefer apartments, and the majority preferred villas (64.5\%). However, an interesting fact is concluded for nationals who all live in villas (8\%), but $2.5 \%$ have preferred apartments (Figure $6 \mathrm{~b}$ ). This can reflect the need of nationals for housing diversity. This implies that typology preferences of the multicultural population are not addressed since the existing market supply serves the work-oriented nature of the migrants. It can be concluded that the diverse housing typologies, which address family living, is a common preference in Doha.

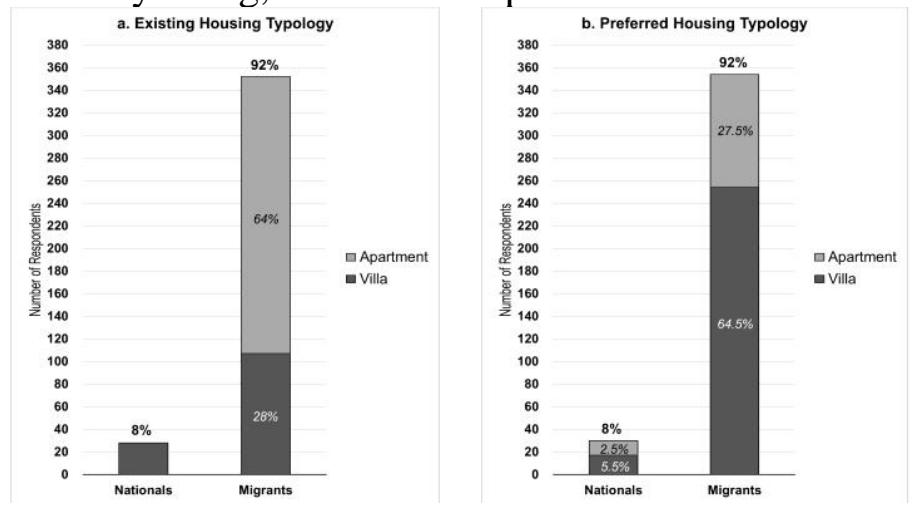

Figure 6. Housing typology preferences (source: the authors based on the questionnaire survey)

It is concluded that housing typology preferences in Doha reflect the cultural origins of the population. The villa typology is dominant in suburban neighbourhoods, which is aligned with the preferences of nationals. It is the most preferred typology where spacious rooms and large living areas 
are provided to accommodate the family-oriented activities and frequent gatherings. However, apartments are the most supplied typology in the market, especially in suburban and waterfront neighbourhoods. The needs and values of the multicultural population should be addressed through a preference-driven supply of housing typologies with proper costs in preferable locations.

In terms of real estate conditions, experts have agreed on the importance of the contribution of the government and the large and small-scale developers in the local housing market. A common agreement is concluded that income groups guide the housing market in Doha. The supply by real estate developers targets particular income groups, in which particular housing areas and typologies are being developed. Some suggestions have emphasized on the role of the government to support real estate developers through regulations and incentives. The main aim is a housing market that is accessible to all cultural groups and income groups.

\section{CONCLUSION AND RECOMMENDATIONS}

According to the analysis, it is realized that among the most prevailing factors affecting urban growth of Doha and its peripheries are the decisions that are posed by the government. A set of recommended actions are developed and summarized the solid outcomes of the paper (Figure 7).

- A decentralization approach for housing expansion is recommended towards other organized suburban centers to the north of Doha.

- Housing policies with respect to zoning should consider mixed of typologies and densities to reduce the effect of social segregation in Greater Doha.

- Revitalize downtown neighborhoods towards lifestyle housing communities that satisfy both nationals and migrants' housing preferences.

- Social housing is seen as a potential remedy to housing inequality and affordability. Therefore, the government should contribute more.

- Clear cooperation between government (regulations) and the real estate developers (housing developments) is required to reduce the pressure on the city's infrastructure through considering nationals and migrants needs. In terms of local economic growth, this would be an important step towards a more balanced housing market.

- Encourage developers to build affordable housing in Doha through governmental incentives.

- Allow housing ownership for migrants towards sustainable economic growth.

- Plan and design walkable neighborhoods and housing communities.

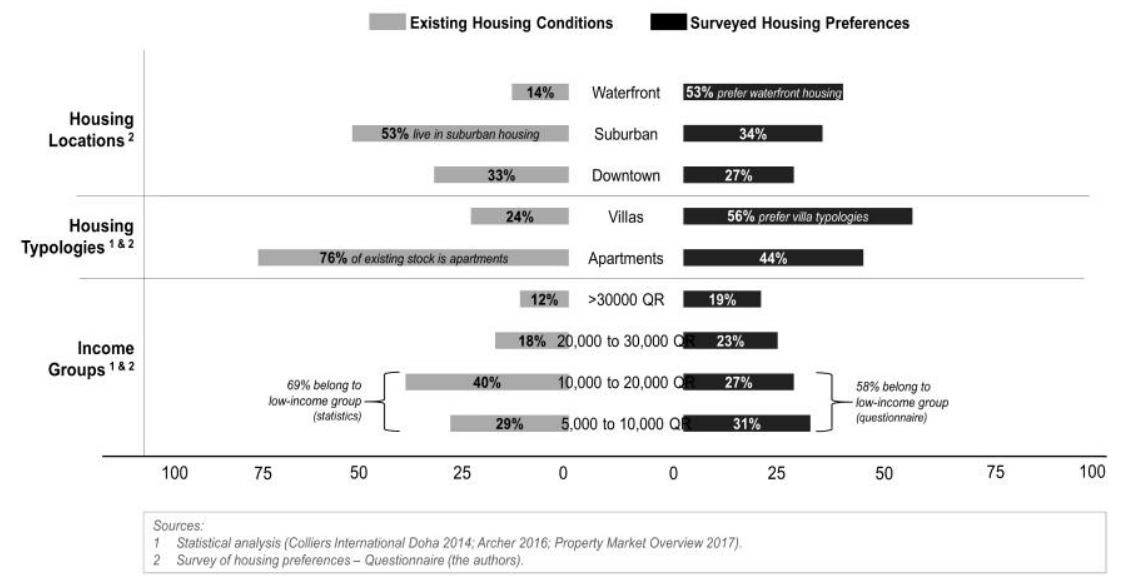

Figure 7. Comparative summary of the existing housing conditions and the surveyed housing preferences in Doha metropolitan (source: the authors based on the statistical analysis and housing preferences analysis)

Most of the experts agreed that the low-income groups would struggle to find a suitable housing unit; rather they share units as a reflection of their need for affordable housing. In terms of the future directions and outlook of the housing market, experts suggest creating a room for migrants to be part of owning homes and considering them as final investors to ensure building a prosperous economy. Additionally, legislation should be cooperated with the design of housing to reduce the pressure on the city's infrastructures and government. Suggestions were introduced to improve the 
policies, which respect the local culture, climate, and context. This includes more opportunity to migrants to own their housing in Doha towards a livable housing market.

\section{AKNOWLEDGEMENT}

This paper was made possible by NPRP grant number [NPRP 07 - 960 - 5 - 135] from the Qatar National Research Fund (a member of Qatar Foundation). The findings achieved herein are solely the responsibility of the authors.

\section{REFERENCES}

Bel-Air, F. (2014). Demography, Migration, and Labor Market in Qatar - Gulf Labor Markets and Migration (GLMM). European University Institute (EUI) and Gulf Research Center (GRC). Retrieved from: http://cadmus.eui.eu/bitstream/handle/1814/32431/GLMM_ExpNote_082014.pdf?sequence=1

Colliers International (2013). Real Estate Market Overview Report - Doha, Qatar, Q2 2013. Colliers International. Retrieved from: http://www.colliers.com//media/files/emea/uae/market-overview/ci_qatar_re_overview_q2_2013.pdf

Colliers International (2014). Doha's Residential Market - Market Performance, Trends, and Affordability. Retrieved from: http://www.colliers.com//media/562F03BEE6D54CA0B7BA140DF287C911.ashx?la=en-GB

Dawkins, C. \& Koebel, C. (2009). Overcoming Barriers to Placing Manufactured Housing in Metropolitan Communities. Journal of the American Planning Association, 76(1), 73-88. http://dx.doi.org/10.1080/01944360903401052

Eddisford, D. \& Carter R. (2017). The Vernacular Architecture of Doha, Qatar. The Journal of the Society for PostMedieval Archaeology, 51(1), 81-107. http://dx.doi.org/10.1080/00794236.2017.1320918

Haybatollahi, M., Czepkiewicz, M., Laatikainen, T., \& Kytta, M. (2015). Neighborhood preferences, active travel behavior, and built environment: An exploratory study. Transportation Research - Part F: Traffic Psychology and Behavior, 29, 57-69. http://dx.doi.org/10.1016/j.trf.2015.01.001

Hunt, J. (2010). Stated Preference Examination of Factors Influencing Residential Attraction. In F. Pagliara, J. Preston, \& D. Simmonds (Eds.), Residential Location Choice: Advances in Spatial Science (pp. 21-59). Berlin: Springer. ISBN 978-3-642-12788-5

Jaidah, I., \& Bourennane, M. (2009). The History of Qatari Architecture 1800-1950. 1st edition, Skira, ISBN-10: 8861307930, ISBN-13: 978-8861307933.

Lee, H., Beamish, J., \& Carucci Goss, R. (2008). Location Preferences of Multifamily Housing Residents. Housing and Society, 35(1), 41-58. http://dx.doi.org/10.1080/08882746.2008.11430557

Ministry of Development Planning and Statistics (2013). Qatar Atlas. 3rd edition, Ministry of Development Planning and Statistics, ISBN: 99921-62-95-3.

Ministry of Development Planning and Statistics (2015). The Simplified Census of Population, Housing and Establishments, 2015. Ministry of Development Planning and Statistics. Retrieved from: https://www.mdps.gov.qa/en/knowledge/Publications/Other/Census\%202015.pdf

Ministry of Municipality and Environment (2015). Archive Department. Doha Satellite Imagery in 2015.

Ouwehand, A. \& Doff, W. (2011). 'What is the use of lifestyle research in housing?' A case study from the Netherlands. Paper presented at the 23rd Conference of the European Network for Housing Research ENHR, France. Retrieved from: https://repository.tudelft.nl/islandora/object/uuid\%3A1680568d-dd40-4792-a14a70b694b391cb. UUID 1680568ddd40-4792-a14a-70b694b391cb

Petkar, A. \& Macwan, J. (2013). Residential Location Preferences: Approaches and Research Avenues. Paper presented at the 4th International Conference on Advances in Civil Engineering, AETACE. Retrieved from: http://searchdl.org/public/book_series/elsevierst/6/21_1.pdf

Pisman, A., Allaert, G., \& Lombaerde, P. (2011). Urban and Suburban Lifestyles and Residential Preferences in a Highly Urbanized Society. Belgeo, 2(1), 89-104. http://dx.doi.org/10.4000/belgeo.6394

Property Market Overview (2017). Musheireb Properties. Retrieved from: http://www.msheireb.com/enus/aboutqatar/propertymarketoverview.aspx

Salama, A., \& Wiedmann, F. (2013). Demystifying Doha: On Architecture and Urbanism in an Emerging City. 1st edition, Ashgate, ISBN: 978-1-4094-6634-5.

Scheiner, J. \& Kasper, B. (2003). Lifestyles, Choice of Housing Location and Daily Mobility: The Lifestyle Approach in the Context of Spatial Mobility and Planning. International Social Science Journal, 55(176), 319-332.

http://dx.doi.org/10.1111/1468-2451.5502011

Shandas, V., Makido, Y., \& Ferwati, S. (2017). Rapid Urban Growth and Land Use Patterns in Doha, Qatar: Opportunities for Sustainability?. European Journal of Sustainable Development Research, 1(2), 1-13. https://doi.org/10.20897/ejosdr.201711

Snoj, J. (2017). Population of Qatar by Nationality. Priya DSouza Consultancy. Retrieved from: http://priyadsouza.com/population-of-qatar-by-nationality-in-2017/

Wiedmann, F., Salama, A., \& Thierstein, A. (2012). Urban Evolution of the City of Doha: An Investigation into the Impact of Economic Transformations on Urban Structures. METU Journal of the Faculty of Architecture (JFA), 29(2), 35-61. DOI:10.4305/METU.JFA.2012.2.2, Online at: http://jfa.arch.metu.edu.tr/archive/02585316/2012/cilt29/sayi_2/3561.pdf 